\title{
Impacto da Violência no Sistema Familiar de Mulheres Vítimas de Agressão
}

\author{
The Impact of Violence in the Family \\ System of Women Victim of Agression \\ Impacto de La Violencia en el \\ Sistema Familiar de Mujeres Víctimas de Agresión
}

Ana Cláudia Wendt dos Santos \& Carmen Leontina Ojeda Ocampo Moré

Universidade Federal de Santa Catarina

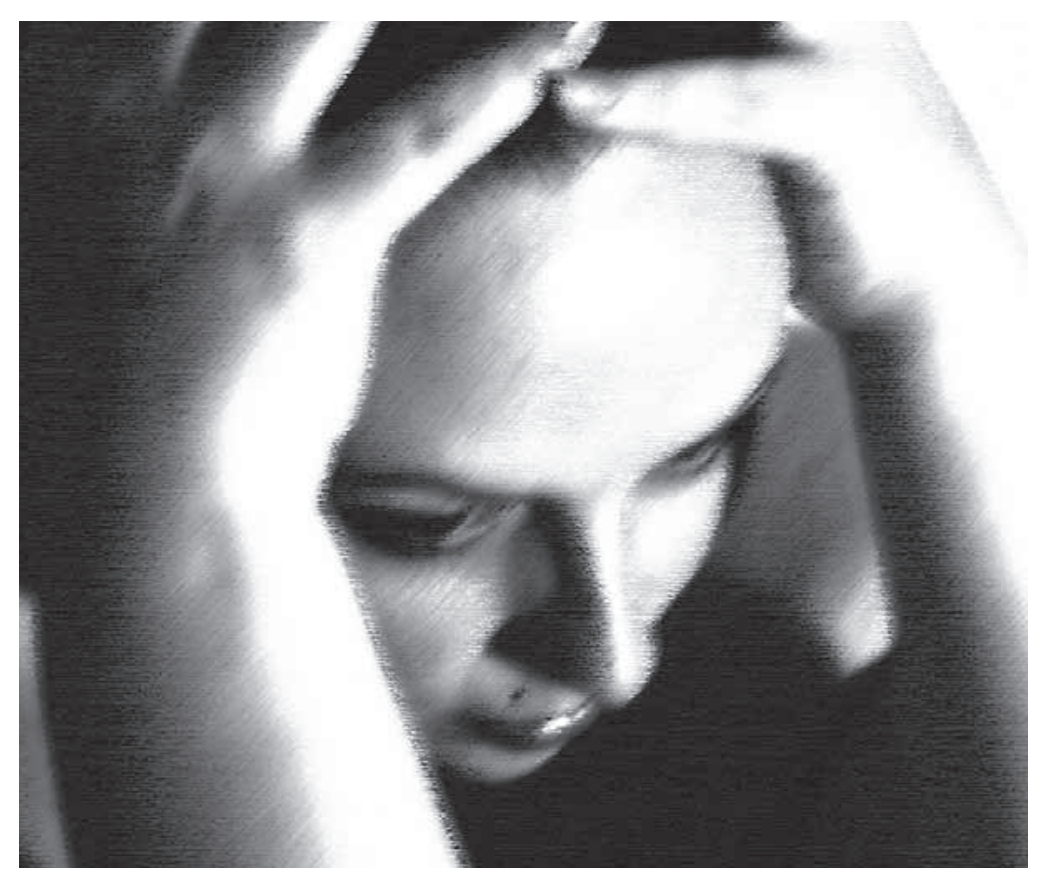


Resumo: Esta pesquisa objetivou caracterizar o impacto da violência na dinâmica relacional familiar, assim como sua transgeracionalidade, em famílias de mulheres que sofreram agressão física. $\mathrm{O}$ estudo foi de natureza exploratório-descritiva e adotou a metodologia qualitativa. As participantes foram 10 mulheres que sofreram violência física e que prestaram queixa em uma Delegacia Especializada de Atendimento à Mulher. A coleta de dados foi realizada através de entrevista semiestruturada, que subsidiou a construção do genograma familiar. Para a análise dos dados, foram utilizados a teoria fundamentada empiricamente (Grounded Theory) e o software Atlas/ti 5.0. Constatou-se um conjunto de justificativas das participantes para terem permanecido ao lado dos agressores, apesar de terem sofrido outras situações de violência e o impacto da violência em crianças e adolescentes que viviam próximos a elas. Com a construção do genograma, evidenciou-se a transgeracionalidade da violência, sendo que os integrantes de suas famílias de origem apresentaram um padrão de relação familiar semelhante ao delas. Compreende-se que os resultados deste estudo reforçam as relações de gênero e a transgeracionalidade da violência como pontos importantes a serem considerados no momento de pensar e implementar pesquisas, ações e políticas referentes às mulheres em situação de violência.

Palavras-chave: Mulheres. Violência na familia. Relações familiares. Conflito conjugal.

Abstract: This study aimed to characterize the impact of violence suffered by women in family relationship dynamics and identify the transgenerational violence in women who suffered physical aggression. The study was exploratory-descriptive and adopted a qualitative methodology. The participants were 10 women who had suffered physical violence and had made a complaint in a police station for the care of women. Data collection was conducted through semi-structured interview which subsidized the construction of the family genogram. For data analysis, the empirical basis theory (Grounded Theory) and the software Atlas / ti 5.0 were used. There are a number of reasons for the participants to have remained with the aggressors, despite having suffered other situations of violence and the impact of violence on children and adolescents who lived next to them. With the construction of the genogram, the transgenerational violence was revealed, and the members of their families of origin had a similar pattern of family relationship. It is understood that the results of this study reinforce gender relations and violence as transgenerational important points to consider when thinking and implementing research, policies and actions related to women in violent situations.

Keywords: Women. Family violence. Family relations. Marital conflict.

Resumen: Esta pesquisa objetivó caracterizar el impacto de la violencia en la dinámica relacional familiar, así con su transgeneracionalidad, en familias de mujeres que sufrieron agresión física. El estudio fue de naturaleza exploratorio-descriptivo y adoptó la metodología cualitativa. Las participantes fueron 10 mujeres que sufrieron violencia física y que presentaron denuncia en una Comisaría Especializada de Atendimiento a la Mujer. La recogida de datos fue realizada a través de entrevista semi-estructurada que subsidió la construcción del Genograma Familiar. Para el análisis de los datos, fue utilizada la Teoría Fundamentada Empíricamente (Grounded Theory), y el software Atlas/ti 5.0. Fue constatado un conjunto de justificativas de las participantes para haber permanecido al lado de los agresores, a pesar de haber sufrido otras situaciones de violencia y el impacto de la violencia en niños y adolescentes que vivían próximos a ellas. Con la construcción del Genograma, se evidenció la transgeneracionalidad de la violencia, siendo que los integrantes de sus familias de origen presentaron un estándar de relación familiar semejante al de ellas. Se comprende que los resultados de este estudio refuerzan las relaciones de género y la transgeneracionalidad de la violencia con puntos importantes a ser considerados en el momento de pensar e implementar pesquisas, acciones y políticas referentes a las mujeres en situación de violencia.

Palabras clave: Mujeres. Violencia Familiar. Relaciones Familiares. Conflicto marital.

A violência sempre foi uma forma de as pessoas se relacionarem para oprimir, dominar e subjugar o outro sobre quem tal ato era exercido, assim como para alcançar determinado fim (Ferrari \& Vecina, 2002; Fuster, 2002). No que tange à violência contra a mulher, movimentos sociais como o feminismo, publicações de pesquisas sobre a situação da mulher no mundo, as sequelas geradas devido às agressões exercidas contra elas (sequelas físicas, psicológicas, familiares e sociais) e seu alto índice de ocorrência foram todos fatores importantes para que qualquer tipo de violência praticado deixasse de ser considerado uma questão da vida privada para se tornar um problema de saúde pública (Souza \& Adesse, 2005; Villela \& Lago, 2007).

Apesar de vários avanços obtidos na direção de erradicar a violência exercida contra 
O uso da

violência física perpetrada

pelo marido

companheiro

ou outro

familiar, mais

do que por um

desconhecido,

tem sido

apontado como

a principal

agressão

exercida contra

a mulher, o

que não quer

dizer que essa

violência não

ocorra sem

articulação com

as demais - a

psicológica,

a sexual e a

negligência

(Azevedo, 1985;

Marcos, 2005) a mulher, como a promulgação da Lei ${ }^{\circ}$ 11.340, mais conhecida como Lei Maria da Penha, é possível verificar ainda hoje o uso da violência contra as mulheres, pois existem certas formas de agressão que são permitidas e, inclusive, toleradas pela sociedade, como, por exemplo, o marido bater na esposa para mantê-la nos limites impostos por ele para a relação conjugal (Aldrighi, 2006). O uso da violência física perpetrada pelo marido companheiro ou outro familiar, mais do que por um desconhecido, tem sido apontado como a principal agressão exercida contra a mulher, o que não quer dizer que essa violência não ocorra sem articulação com as demais - a psicológica, a sexual e a negligência (Azevedo, 1985; Marcos, 2005)

Embora as estatísticas referentes à violência exercida contra a mulher sejam alarmantes, sabe-se que dificilmente se obtém o número real de mulheres que sofrem algum tipo de agressão diariamente. Tal fato ocorre justamente porque muitas mulheres são agredidas dentro das próprias casas, inicialmente pelo pai e pelo irmão, e posteriormente pelo marido ou namorado (Bedone \& Faundes, 2007; Villela \& Lago, 2007). Subjugadas nesse processo histórico de construção de relações violentas, elas se calam, uma vez que temem que um ato violento mais grave ocorra contra elas, pois a probabilidade de sofrer uma agressão ainda mais severa do parceiro, incluindo o homicídio, aumenta significativamente depois que a mulher decide abandonar a relação conjugal (Ferrari \& Vecina, 2002).

Nesse sentido, mulheres agredidas dentro da própria família tendem a minimizar o problema, desejando acreditar que o marido/ companheiro, pai ou irmão não seja tão violento como parece. Concomitantemente, elas experimentam vergonha, culpa e baixa autoestima por viverem esse tipo de situação, além de medo de ficarem sozinhas. Como consequência disso, acabam se isolando de seus contatos sociais, restringindo-se ao ambiente doméstico e, desse modo, afastando-se de uma possível rede de apoio, o que contribui para se tornarem ainda mais prisioneiras de uma relação baseada na violência (Bedone \& Faundes, 2007; Monteiro \& Souza, 2007; Villela \& Lago, 2007).

Outro aspecto a ser considerado diz respeito à condição social e econômica da população feminina. Verifica-se que ainda há mulheres que recebem menos do que os homens, apesar de realizarem as mesmas tarefas que eles. As desigualdades financeiras existentes entre os gêneros servem para gerar pontos de conflito entre o casal, e dão maior poder de controle a quem possui melhor condição socioeconômica, o que cria motivos para que a violência ocorra (Aldrighi, 2006; Monteiro \& Souza, 2007). Além disso, referida desigualdade também serve para aumentar a fragilidade, a vulnerabilidade e a desvalorização na qual a mulher se encontra, uma vez que, com isso, ela não se vê em condições de sustentar a família. Desse modo, resta a ela, muitas vezes, continuar na relação ou voltar para o agressor como meio de conseguir se manter e de manter seus filhos (Alberdi, 2005; Carneiro \& Oliveira, 2008).

É possível contatar, também, que o grau de instrução das mulheres agredidas é baixo, o que limita suas possibilidades de escolha profissional, além de fazer com que optem por profissões pouco valorizadas socialmente e de baixa remuneração, quando resta a elas ficarem relegadas ao trabalho de casa, tornando-se completamente dependentes do marido/companheiro para sobreviver. Assim, trata-se de mais um fator que converge na direção de conservar a mulher inferiorizada diante dos homens e, destarte, na condição de subalterna a eles (Alberdi, 2005).

Além disso, a violência psicológica a que muitas mulheres são submetidas na relação conjugal, 
através de xingamentos, humilhações, depreciação de seu modo de vestir e desqualificação de seu corpo, entre outros, só faz aumentar sua insegurança e diminuir sua autoestima, tornando-a cada vez menos capaz de enfrentar as agressões sofridas. Assim, "sem força econômica, sem força psicológica, (a mulher) viverá uma condição de permanente desamparo aprendido, credencial adequado para desempenhar o papel de vítima nos episódios de violência física, como exacerbação de um padrão não igualitário de relações sociais de gênero" (Azevedo, 1985, p. 76) (grifos do autor).

Outros fatores também listados pelas pesquisas (Ministério da Saúde, 2002; Silva, Coelho, \& Caponi, 2007) como possíveis motivos para as mulheres continuarem em uma relação em que há violência são: história familiar na qual havia agressão entre os pais ou pessoas próximas a elas, ela mesma ter sido vítima de violência física, negligência ou abuso sexual, entre outros, quando criança ou adolescente, o uso do casamento como forma de sair de casa, o desejo de proteção, a dependência e a estabilidade no casamento, a crença na mudança de atitude do marido/ companheiro, a crença na incapacidade de viver sem o marido/companheiro e sem um pai para os filhos, a desresponsabilização do marido/companheiro ao atribuir a fatores externos (como desemprego, uso de drogas, etc.) o comportamento agressivo exibido por ele, a exagerada valorização de atributos apresentados pelo marido/companheiro, como o fato de ser trabalhador e bom pai, como forma de amenizar a violência exercida contra ela, o medo de, com a separação, perder a guarda dos filhos ou ter que sair de casa e a falta de apoio da família e de uma rede social.

Cabe destacar que, no campo do conhecimento sobre o tema da violência contra a mulher, verifica-se a presença de correntes teóricas advindas de estudos feministas que ora analisam a mulher como vítima e cúmplice da situação de agressão, ora como vítima, mas também como um sujeito autônomo, às vezes exclusivamente como cúmplice, sendo essas controvérsias problematizadas mais profundamente a partir da década de 1990 (Cantera, 2007; Santos \& Izumino, 2005).

Considera-se que, ao avaliar a mulher em situação de violência, fala-se de um processo interacional que não pode ser concebido como construção individual, mas como trama relacional, na qual todas as partes envolvidas se afetam recursivamente, ou seja, nas relações conjugais, familiares e sociais, as ações entre seus integrantes tanto podem gerar atitudes de violência como condições de submissão à mesma. Assim, quando se concebe as situações de violência em um processo de construção relacional, a tomada de posição como agressor, como vítima ou como cúmplice, produto desse processo de construção, dependerá diretamente do contexto em que a situação de violência ocorrer.

Ao se levar em conta que os homens (maridos, companheiros, pais, irmãos) são os principais agressores das mulheres, pode-se dizer que a violência contra a mulher "é também uma forma de violência de gênero" (Narvaz \& Koller, 2006, p. 8). Entende-se por gênero uma "construção cultural coletiva dos atributos da masculinidade e feminilidade" (Ministério da Saúde, 2002, p.13).

Nessa direção, cabe destacar os estudos sobre a influência das diferenças de gênero, como desigualdades histórica e socialmente construídas entre homens e mulheres, e que ainda hoje são um dos elementos fundamentais para compreender a complexidade do fenômeno da violência exercida contra a mulher. Entre os fatores que servem de base de sustentação para a ocorrência das desigualdades entre os gêneros e para a sua perpetuação até os dias de hoje, está o machismo ainda presente em nossa 
sociedade e que contribui para a prevalência da compreensão de que o homem é mais forte e mais competente do que a mulher, não apenas fisica mas também psicologicamente mais bem preparado do que ela (Azevedo, 1985; Cantera, 2007).

Outro elemento que constitui a base sobre a qual se sustentam as desigualdades de gênero diz respeito ao advento do patriarcado, que, segundo Azevedo (1985) e Alberdi (2005), é a forma institucionalizada que o machismo assumiu, já que legitima o homem como único chefe da família. Assim como o machismo, o patriarcado não é mais tão dominante, mas também não desapareceu completamente, pois, como afirma Alberdi, "o uso da força como método para resolução de conflitos se legitima quando a exercem os homens em um modelo social que se apóia na supremacia masculina" (2005, p. 23).

Do mesmo modo, Narvaz e Koller (2006) constataram, com base em seus estudos, que algumas famílias de hoje em dia ainda tentam viver conforme o modelo de família patriarcal, nuclear, monogâmica e burguesa, procurando valorizar a tradição, a hierarquia e a obediência da mulher em relação ao homem e a das crianças e dos jovens em relação ao homem adulto, por considerarem que esse seja o padrão correto de se estruturar um ambiente familiar.

Contudo, tal constituição familiar e social não teria condições de se formar nem de se manter se não fosse pela educação diferenciada oferecida às crianças. Desde a mais tenra idade, elas aprendem a incorporar um gênero, ou seja, aprendem quais comportamentos e emoções cabem a um menino e a uma menina expressar e como cada um deve se vestir, entre outros, de modo que a pessoa possa se tornar tanto um orgulho para a família quanto ser socialmente aceita (Alberdi, 2005; Azevedo, 1985; Marcos, 2005).
Outra situação que caracteriza a violência exercida contra a mulher por seu marido/ companheiro é que esta transcende os limites da relação existente entre os dois e afeta também crianças e adolescentes. Pesquisas (Aldrighi, 2006; Carneiro \& Oliveira, 2008; Cecconello, De Antoni, \& Koller, 2003; Ferrari \& Vecina, 2002; Silva, Coelho \& Caponi, 2007; Tiwari, Chan, Fong, Leung, Brownridge, Lam, Wong, Lam, Chau, Chan, Cheung, \& Ho, 2008) evidenciam que a violência ocorrida entre os pais pode gerar filhos agressivos e delinquentes, uma vez que a agressão é aprendida pelas crianças como forma normal de interação entre as pessoas, o que aumenta a probabilidade de esse comportamento ser repetido em suas relações presentes e futuras.

Somado a isso, crianças e adolescentes que vivem a violência exercida contra a mulher podem igualmente sofrer sequelas físicas e psicológicas semelhantes às da própria vítima de agressão, desde a ocorrência de ansiedade, dores de cabeça, úlceras, sentimentos de culpa e depressão até as relacionadas ao processo de desenvolvimento infantil, tais como problemas na fala, dificuldades de aprendizagem e de concentração (Silva et al., 2007).

Desse modo, a violência perpetrada contra a mulher dentro da família, ao repercutir de tal maneira em crianças e adolescentes, pode formar um ciclo contínuo do problema, ou o que se chama de transgeracionalidade da violência, que nada mais é que uma herança transmitida de uma geração a outra com o amparo social e cultural (Narvaz \& Koller, 2006). Tal evidência foi igualmente destacada por Carter e McGoldrick (1995), que incluem os elementos intergeracionais como aspectos importantes de serem levados em conta na hora de se tentar entender o desenvolvimento familiar, já que uma geração possui a capacidade de afetar o modo como se estabelecerá a dinâmica familiar da geração seguinte. 
1 Dinâmica

relacional familiar

- modo como

os integrantes

de uma família

se relacionam

e mantêm seus

vínculos a partir

da interação

entre eles, como

lidam com seus

problemas e

conflitos, e com

base nas relações

hierárquicas e

papéis delimitados

existentes dentro

desse sistema

(Cerveny, Berthoud, Bergami, \& Luisi, 1997; Cerveny \& Berthoud, 2002)
Como é possível verificar, são vários os elementos que, articulados, caracterizam e constituem a violência contra a mulher e ajudam a perpetuá-la, bem como contribuem para criar e alimentar a vulnerabilidade feminina. Não obstante, a finalidade deste artigo não é esgotar as razões pelas quais a violência contra a mulher ocorre, mas chamar a atenção para a complexidade de sua constituição e dinâmica. Conforme Azevedo destaca, o que é preciso é sempre levar em consideração que se trata de um fenômeno "de múltiplas determinações, sofrendo o efeito de inúmeras mediações que não se pode ignorar se se quiser compreendê-lo em toda sua plenitude" (1985, p.18).

Assim sendo, é a partir da perspectiva exposta acima que o presente estudo objetivou descrever o impacto da violência sofrida por mulheres na dinâmica relacional familiar ${ }^{1}$, bem como pretendeu identificar a transgeracionalidade da violência na família de mulheres que sofreram agressão física.

\section{Método}

Esta pesquisa seguiu os pressupostos da metodologia qualitativa, sendo também exploratório-descritiva, pois almejou descrever e caracterizar aspectos da vida de mulheres que denunciaram a violência do qual eram vítimas em uma Delegacia Especializada de Atendimento à Mulher.

\section{Caracterização do campo de pesquisa}

O contato com os sujeitos da pesquisa foi estabelecido a partir de uma Delegacia Especializada de Atendimento à Mulher, localizada em uma cidade do sul do Brasil.

\section{Participantes}

De um total de 40 mulheres contatadas que apresentaram queixa em uma Delegacia Especializada de Atendimento à Mulher,
10 aceitaram participar do presente estudo. A partir da sexta e da sétima entrevistas, observou-se a saturação dos dados obtidos, na medida em que se verificou que as informações fornecidas já respondiam aos objetivos estabelecidos, evidenciando-se tanto as regularidades dos conteúdos como os aspectos diferenciais de cada participante.

\section{Critérios de inclusão e exclusão das participantes}

As entrevistadas foram selecionadas segundo os seguintes critérios: 1) a participante ser maior de 18 anos; 2) a situação de violência ter ocorrido no mínimo um mês antes do contato da pesquisadora com as entrevistadas; 3) apresentar condições de compreender os objetivos da pesquisa e de estabelecer uma comunicação razoavelmente clara com a entrevistadora.

\section{Instrumentos}

A coleta de dados foi feita por meio da realização de entrevista semiestruturada, que também subsidiou a confecção do genograma (Asen \& Tomson, 1997; Carter \& McGoldrick; 1995) no momento da realização das entrevistas com cada participante deste estudo.

A efetivação da entrevista semiestruturada implicou compor um roteiro de perguntas elaboradas de forma tal que foram respondidas por todas as entrevistadas, adotando-se uma formulação flexível, de modo que a sucessão das questões e os detalhes ficaram por conta do discurso das participantes e da dinâmica da entrevista. O roteiro da entrevista semiestruturada desta pesquisa foi constituído pelos seguintes temas: 1 . dados de identificação (nome/somente as letras iniciais, idade, nível de escolaridade, ocupação, estado civil, renda familiar), 2. dados da ocorrência (breve descrição do que aconteceu, se havia sofrido algum tipo 
de situação semelhante antes e como foi que ocorreu), 3. situação emocional da entrevistada (que sentimentos, emoções ou comportamentos passou a experimentar após o ocorrido, como estava hoje, qual a maior dificuldade que passou a enfrentar após o ocorrido, o que fez para enfrentar as dificuldades apresentadas, o que fazia atualmente para sentir-se melhor e lidar com o que aconteceu); 4. genograma (como eram as relações com a família de origem, se já havia acontecido com outra pessoa da família a mesma situação que havia ocorrido com ela, se havia tido outras relações conjugais em que havia sofrido violência). É importante salientar que esses tópicos foram norteadores da entrevista para a pesquisadora, tendo sido prezado, sempre, o fluxo do diálogo, com os itens introduzidos de maneira a não interferir no mesmo.

As entrevistas duraram cerca de 60 minutos e constituíram uma ferramenta relevante para contextualizar o comportamento das participantes, pois fizeram emergir sentimentos, atitudes, motivos, intenções e valores (Biasoli-Alves, 1998).

Com o genograma (Asen \& Tomson, 1997; Carter \& McGoldrick, 1995), procurouse verificar, a partir do relato de quatro gerações das informantes (seus avós, seus pais, ela mesma e seus filhos), se havia ou não um padrão de violência no interior de suas famílias de origem materna e paterna. A escolha por tal instrumento de pesquisa teve o intuito de integrar os dados obtidos com a entrevista semiestruturada.

\section{Procedimentos}

A presente pesquisa foi submetida à aprovação pelo Comitê de Ética e Pesquisa com Seres Humanos da Universidade Federal de Santa Catarina - UFSC (Parecer Consubstanciado Projeto $n^{\circ} 393 / 2007$ ), e por todos os níveis decisórios da Delegacia Especializada de Atendimento à Mulher.

\section{Coleta de dados}

A coleta de dados ocorreu através da articulação com um psicólogo que atuava na Delegacia Especializada de Atendimento à Mulher. A partir desse contato, a pesquisadora pôde acessar os Boletins de Ocorrência e Termos Circunstanciados existentes naquela instituição para fazer a triagem dos nomes e números de telefone das mulheres com o perfil estabelecido para serem entrevistadas.

Com relação aos encontros para entrevista com as participantes desta pesquisa, sete ocorreram na própria casa da entrevistada e três no Serviço de Atendimento Psicológico (SAPSI) da instituição educacional de referência da pesquisadora. Antes do início das entrevistas, explicações orais e escritas sobre o conjunto da pesquisa eram fornecidas às participantes, e a entrevista apenas começava depois da permissão da informante e da sua assinatura do Termo de Consentimento Livre e Esclarecido. A pesquisadora também ficou à disposição das participantes, após a realização das entrevistas, caso houvesse mobilização emocional decorrente da temática abordada. As entrevistas foram gravadas e transcritas na íntegra.

\section{Análise dos dados}

A análise dos dados foi realizada com base na Grounded Theory (teoria fundamentada empiricamente), proposta por Strauss e Corbin (1990). O processo de análise envolveu as seguintes etapas: 19o) interação com os dados, realizado à medida que foram coletados e que se desenhavam à luz do objetivo da pesquisa, através de leituras sucessivas do material textual das entrevistas, o que promoveu uma análise em profundidade dos dados e possibilitou maior compreensão do significado das experiências descritas pelas participantes, $2^{\underline{9})}$ os dados foram, então, desmembrados, examinados e comparados, possibilitando 
a elaboração de categorias de acordo com suas especificidades, 39 ) as categorias foram nomeadas a partir da emergência de pontos nucleares que foram se mantendo na diversidade e complexidade dos dados, procurando-se chegar à representação dos significados dos códigos agrupados, 4으) a partir das categorias principais, relacionaramse subcategorias e seus respectivos elementos de análise, os quais auxiliaram na descrição, compreensão e sustentação das categorias principais, e 5o) os dados obtidos a partir das entrevistas e da literatura apresentada sustentaram a nomeação das categorias, que, tomadas em seu conjunto, levaram a uma compreensão integrada do fenômeno central deste artigo, que é o impacto da violência no sistema familiar de mulheres vítimas de agressão.

Como recurso auxiliar, foi utilizado o software Atlas/ti 5.0, que constitui um programa de análise de dados qualitativos. As entrevistas transcritas foram inseridas no referido programa, e, a partir dos seus recursos, houve condição de a pesquisadora construir e organizar as categorias principais e seus elementos de análise (Murh, 2004).

Assim, tendo como referência as análises realizadas em profundidade dos conteúdos das entrevistas e os dados obtidos com a confecção do genograma, foram construídas quatro categorias de análise. Cabe ressaltar que as informações alcançadas estão incluídas em uma totalidade complexa, com diversas conexões, salientando-se, dentro delas, as entrevistadas, suas famílias e os aspectos socioculturais envolvidos. Portanto, a compreensão adequada dos dados apresentados implica vê-los no seu conjunto, e não isoladamente, pois afetamse mutuamente, destacando-se, com isso, a dinâmica da relação existente entre eles e dentro da qual adquirem sentidos (Moré, 2000).

\section{Resultados e discussão}

Com o intuito de melhor contextualização das categorias resultantes da análise de conteúdo realizada, destacam-se, em um primeiro momento, as principais características das participantes deste estudo.

\section{Caracterização das participantes}

Faixa etária: oito das dez entrevistadas tinham entre os 30 e 40 anos. Estado civil: cinco declararam-se solteiras (embora quatro morassem com os parceiros) e três afirmaram que viviam com os companheiros. Apenas uma delas declarou-se casada e outra, separada, mostrando o predomínio de relações não oficiais entre as participantes. Grau de escolaridade: destacou-se a pouca formação escolar, havendo quatro mulheres que possuíam o ensino fundamental incompleto, duas com o ensino fundamental completo, duas com o ensino médio completo, uma com o ensino superior incompleto e uma com o ensino superior completo. Principal ocupação: as principais ocupações citadas por elas foram as de doméstica (2 participantes), do lar (2 entrevistadas) e 2 se encontravam desempregadas. Com respeito às demais, 1 era cozinheira, outra assistente administrativo, uma auxiliar de serviços gerais e outra auxiliar de caixa. Renda familiar: a renda familiar declarada ficou entre 1 salário mínimo mensal (3 entrevistadas), 1 salário mínimo e meio mensal (2 participantes), 2 salários mínimos mensais ( 1 entrevistada) e 3 salários mínimos mensais (4 participantes), demonstrando o contexto de necessidade/escassez em que essas mulheres viviam. Principal agressor: 9 das 10 mulheres entrevistadas foram agredidas pelo próprio marido/companheiro, e 2 dessas mulheres foram também agredidas pelo filho. Uma sofreu violência física do cunhado. Número de filhos: 5 participantes tinham três filhos, 2 tinham dois filhos, 1 tinha cinco filhos, 1 tinha um filho e 1 não tinha filhos. 


\section{Ciclo de repetição da violência}

Nesta categoria, foram apresentados os elementos de como se estabeleceu o ciclo de repetição da violência entre as participantes desta pesquisa. Para 9 das 10 entrevistadas, foi a primeira relação conjugal em que sofreram violência, além de ter havido vários outros momentos da vida do casal em que elas foram agredidas, inclusive com o pedido de intervenção policial.

Um dos motivos dados pelas participantes para continuar na relação com o agressor foi por "ficarem com pena dele não ter onde morar". O sofrimento esboçado pelo companheiro de uma das entrevistadas, por exemplo, parece tê-la feito acreditar que talvez ele pudesse mudar e, em função disso, não voltar a cometer agressões verbais e físicas contra ela, apesar de essa mesma entrevistada ter relatado que seu companheiro já tinha "ido e voltado umas dez vezes", e nem por isso havia interrompido as agressões dirigidas a ela. Tal atitude, entretanto, confirma o que foi também constatado pelo Ministério da Saúde (2002) e por Silva et al. (2007), ou seja, que uma das razões pelas quais as mulheres voltam para o agressor é justamente por acreditar que ele modificará sua atitude e que, assim, não voltará a ser violento como antigamente.

Também houve casos em que a possibilidade de a entrevistada tentar novamente constituir uma família com o companheiro foi decisiva no momento de escolher continuar ou não o envolvimento com ele, situação essa que vai ao encontro das constatações feitas por Narvaz e Koller (2006), que verificaram que ainda hoje é importante para as mulheres manter a unidade familiar, já que o modelo a ser alcançando continua sendo o da família nuclear e burguesa.

Do mesmo modo, houve a tentativa, pelas participantes, de amenizar a situação dos agressores a partir do destaque das qualidades que possuíam, serem "bons maridos" ou "bons pais", por exemplo, como forma de justificar o fato de não terem prestado queixa anteriormente ou de não terem levado o processo contra eles adiante: "Ele não é drogado, ele não bebe, não fuma, não joga, não é nada disso, mas só que nunca se sabe, né? Perder ele... nem todo pai é que nem ele" (Violeta). Destaca-se, com isso, a tentativa das entrevistadas em minimizar a violência sofrida para se convencerem de que o companheiro não era tão violento quanto parecia.

Ainda no que tange aos motivos que deram para a retirada da queixa policial, ou para não terem dado seguimento ao processo contra os agressores, uma das entrevistadas alegou que já estava cansada e que, caso conseguisse um emprego, ficaria sem tempo para comparecer às audiências do Fórum, talvez por antecipar a demora até que o caso fosse concluído.

Para outra participante, o motivo apresentado foi o de "dar uma chance", possivelmente porque o elemento de maior peso, novamente, tenha sido a necessidade de preservar a harmonia familiar, já que o agressor era seu cunhado. Além disso, a decisão foi tomada pela entrevistada juntamente aos pais, que exerceram certa pressão para que o processo não fosse levado adiante. Contudo, a entrevistada em questão não deixou de expressar sua contrariedade quanto à escolha feita, quando afirmou que tal decisão passava por cima dos princípios de justiça que ela acreditava que deveriam ser preservados. Nessa situação, também se pôde verificar que o valor da família se sobressaiu ao valor do indivíduo, assim como a preservação da imagem do homem em detrimento de se fazer justiça à mulher, o que serve para alimentar as desigualdades de gênero.

No entanto, a razão levantada em maior número de vezes pelas participantes para não terem seguido adiante com as denúncias feitas contra os agressores foi o fato de eles serem o pai de seus filhos. Para uma das entrevistadas, a preocupação foi preservar a relação paterna e também não ser acusada futuramente pelo 
O fato de ganharem pouco, ou de terem que depender do companheiro para sobreviver, apenas

favoreceu o aumento da vulnerabilidade e do desamparo, bem como a diminuição da autoestima dessas mulheres, como apontado por Azevedo (1985) e Carneiro e Oliveira(2008). filho de ter colocado o pai na cadeia. Outra participante, além de justificar ter aceitado o pedido do filho para trazer o pai de volta para casa, não tinha com quem deixar a criança quando precisava sair para o trabalho. Já outra entrevistada alegou ter conseguido chegar a um acordo com o parceiro, mas também afirmou que se comovia com a reação de alegria da filha quando seu companheiro e pai desta ia visitá-los.

Nesse sentido, é preciso levar em consideração a perspectiva das participantes de terem que criar os filhos, ainda pequenos, sozinhas, o que foi apontado por alguns estudos (Ministério da Saúde, 2002; Silva et al., 2007) como um dos motivos pelos quais as mulheres não denunciam os maridos/ companheiros que as agridem. Além disso, oito das dez entrevistadas trabalhavam fora, e poucas podiam contar com o auxílio de parentes ou vizinhos para tomar conta dos filhos enquanto estavam em seus serviços.

Outro fator que pode auxiliar na compreensão dos motivos que levaram essas mulheres a terem optado por continuar na relação com os agressores pode ser observado a partir das dificuldades que elas passaram a enfrentar com a saída deles de casa. Levandose novamente em conta a necessidade/ escassez em que algumas delas viviam, a dificuldade financeira foi uma variável que inevitavelmente acabou surgindo em seus relatos. A maior parte das entrevistadas tinha um rendimento mensal pequeno para se sustentar e também para sustentar os filhos. O fato de ganharem pouco, ou de terem que depender do companheiro para sobreviver, apenas favoreceu o aumento da vulnerabilidade e do desamparo, bem como a diminuição da autoestima dessas mulheres, como apontado por Azevedo (1985) e Carneiro e Oliveira(2008).

De acordo com Aldrighi (2006) e Monteiro e Souza (2007), a diferença de rendimento entre o casal tem, ainda, a função de possibilitar que novas agressões sejam cometidas contra a mulher, já que seu marido/companheiro sabe que ela não tem como se sustentar sem o seu provento. Portanto, com a autoestima baixa e sem poder viver por si própria, resta à mulher se submeter às regras do parceiro.

Contudo, para continuar na relação com o agressor, é preciso que essas mulheres de alguma forma tenham compactuado com o complô do silêncio, ou seja, é preciso que tenham consentido em viver sem poder falar das agressões sofridas, apesar de estas serem vistas pelos integrantes de sua rede pessoal significativa (Sluzki, 1997), como se verifica no depoimento abaixo:

Esses dias ela (filha do companheiro) ligou e ninguém perguntou nada, ninguém tocou no assunto (...); a minha mãe acho que sabe, mas a minha mãe não toca no assunto (...) e eu também não toco (...) Tem assunto que eu não conto pra ela, né, já pra não incomodar ela. (Magnólia)

Parece que, por não falarem com os familiares sobre as agressões sofridas, as entrevistadas acreditavam que os estavam poupando de terem que lidar com algo tão delicado e difícil que é a violência exercida dentro da própria família. Além disso, ao silenciarem sobre esse assunto, também evitavam sentir vergonha por estarem passando por esse tipo de situação. No entanto, essas mulheres não perceberam que, ao se aliarem ao complô do silêncio, acabavam contribuindo para ficarem sozinhas e, principalmente, para aprofundar sua solidão, já que não podiam contar com os outros para vencer suas dificuldades. Por sua vez, quanto mais ficavam sozinhas e solitárias, mais reforçavam sua dependência do agressor, pois não tinham acesso a uma possível rede de apoio para conseguir enfrentá-lo, conforme alertado por Bedone e Faundes (2007) e Villela e Lago (2007).

Tal situação serviu, ainda, de incentivo para que novas agressões acontecessem, já que o agressor sabia que ninguém teria conhecimento do que havia realmente 
ocorrido e que, inclusive, uma nova denúncia dificilmente seria realizada contra ele, como os estudos de Fuster (2002) e Ferrari e Vecina (2002) destacaram.

Apesar de suportarem as agressões caladas, algumas entrevistadas acabaram reagindo às violências perpetradas contra elas, através de agressões físicas igualmente dirigidas aos companheiros. Uma dessas agressões ocorreu através de uma surra de varinha, e foi, inclusive, denunciada na delegacia de polícia. No entanto, a entrevistada não deixou claro se a surra de varinha foi uma resposta a uma agressão sofrida ou uma livre iniciativa contra o companheiro. No entanto, é interessante observar aqui que o ato ou comportamento agressivo constituiu uma reação imediata que se sustenta nas histórias individuais de ambos os cônjuges, como uma única possibilidade de resposta diante de situações-limite, geradoras de violência familiar.

Outra participante, além de estar cansada das agressões desferidas pelo companheiro, também alegou falta de estrutura financeira e emocional para suportar todo o processo movido contra ele, o que a levou a agredi-lo fisicamente:

(...) Muita gente desiste na metade do caminho por causa disso, porque não tem, assim, estrutura financeira, nem emocional, né? (...) E aí às vezes pode chegar até num ponto que você vai deixar de ser vítima. (...) Eu tive umas três, quatro vezes assim (...) que eu fui pra ci... (bater no companheiro) fui. (...) Fui, fui, fui e fui de uma maneira que eu fiquei com medo, com medo de mim. (Iris)

Segundo uma pesquisa realizada por Scaranto, Biazevic e Michel-Crosato (2007), não são poucas as mulheres que reagem verbalmente ou fisicamente às agressões recebidas. Já com base nos estudos de Narvaz e Koller (2006), pode-se entender que as agressões desferidas pelas entrevistadas contra os maridos/companheiros foram um dos recursos dos quais elas puderam se valer para, pelo menos naquele momento, transgredirem as regras impostas por eles, em função da revolta vivida pela opressão a que eram submetidas dentro do contexto familiar.

\section{Fragilização da relação parental}

Nessa categoria, congregaram-se as perspectivas das participantes sobre as repercussões geradas em seus filhos/sobrinho em função das agressões que sofreram. Em princípio, essas crianças apareceram como vítimas indiretas de uma relação conjugal/ familiar em que havia violência, conforme ficou caracterizado no depoimento a seguir:

O meu marido me bateu, me agrediu na frente da minha filha, ela tava no colo, né? Que eu tava com ela no colo, que ela é pequena, tem um ano (...) depois disso, no mesmo dia ela andou, ela falou, ela não fica sem mim, nem se eu vou no banheiro ela tem que ir junto. Ela chora bastante. Antes, quando eu tava lá com ele, ela ficava aqui ca minha mãe numa boa, assim, e agora eu vou ali no portão, assim, ela chora muito. (...) Ela mudou assim da água pro vinho (...) ela ficou bem diferente (...) ela ficou bem, assim, traumatizada, né? (Rosa)

Na situação descrita, é importante observar que só o fato de ver a cena de agressão foi suficiente para gerar repercussões emocionais e comportamentais na criança. Tal dado corrobora os obtidos por Silva et al. 2007, que afirmam que crianças que presenciam violência conjugal/familiar tendem a sofrer sequelas sociais e psicológicas parecidas com as da própria vítima.

Em outros casos, os filhos foram vítimas diretas das ameaças e agressões verbais e físicas desferidas pelos agressores, sendo que algumas dessas crianças apresentaram, do mesmo modo, sequelas psicológicas e comportamentais em decorrência da violência sofrida. A esse respeito, a principal reação verificada pelas entrevistadas em seus filhos foi a de medo de serem novamente agredidos ou, inclusive, mortos em função das surras e das ameaças feitas contra eles pelo próprio 
pai/padrasto. Em consequência, eles não queriam mais sair de casa, deixaram de ir à escola, ou precisavam estar em companhia da mãe para se sentirem protegidos. Podese verificar, desse modo, e conforme estudo realizado pelo Banco Interamericano de Desenvolvimento (Ministério da Saúde, 2002), o quanto viver com pais violentos prejudicou o perfil social dessas crianças, seu rendimento escolar e sua condição psicológica.

Outra situação mencionada pelas entrevistadas foi a frequência com que seus filhos foram utilizados como instrumento dentro do jogo familiar violento estabelecido entre o casal. Em algumas situações, o filho foi levado embora pelo agressor quando este resolveu sair de casa, além de ter sido colocado contra a mulher agredida; em outras, solicitou-se ao filho que denunciasse o agressor, que era seu pai, o que lhe gerou muito medo. Eles também tiveram que suportar os desdobramentos de viverem com pais separados, e com mãe que havia tentado o suicídio devido à repercussão das agressões sofridas.

Os filhos das entrevistadas igualmente sofreram as consequências do pedido de ajuda da mãe à polícia. Pelos menos duas crianças foram colocadas dentro da viatura policial sentadas entre o pai e a mãe para evitar que novas agressões ocorressem entre o casal. Somado a isso, uma delas teve que permanecer durante horas dentro da delegacia até a mãe formalizar a queixa, além de ter assistido o pai ser preso, já que ele havia sido pego em flagrante agredindo a companheira.

Contudo, embora tenham presenciado cenas da mãe sendo agredida e também tenham sido vítimas das mesmas agressões dirigidas a elas, ver o próprio pai ser preso, sentir a sua ausência dentro de casa e não saber como estava vivendo depois da separação foram acontecimentos que causaram muito sofrimento aos filhos, conforme as entrevistadas. Somente uma das filhas das participantes decidiu morar longe da mãe, uma vez que não conseguia se relacionar com o companheiro desta, e devido à aflição que sentia ao ver as agressões desferidas contra a entrevistada.

Uma consequência igualmente trágica de todo esse quadro foi o filho tornar-se também sujeito da violência exercida dentro da família. Duas entrevistadas, além de terem sido agredidas verbal e fisicamente pelos companheiros, sofreram agressões perpetradas pelos próprios filhos:

(...) Me xingava de tudo: tu não é minha mãe, tu é o diabo, tu é o demônio (...) Corpo de Delito eu fiz do filho, é... dois Corpo de Delito contra o filho, que ele me deu um empurrão dali, lá do coisa, me jogou naquele guarda-roupa, não tem? Eu fiquei toda roxa, caí (...) Ele empurrou de lá e quase caí em cima dele. Ele empurrou, me mordeu, tudo. (Hortência)

Tal fato confirma o que se tornou quase um consenso entre diversos estudiosos (Aldrighi, 2006; Carneiro \& Oliveira, 2008; Cecconello, De Antoni \& Koller, 2003; Ferrari \& Vecina, 2002; Narvaz \& Koller, 2006; Silva et al., 2007; Tiwari, Chan, Fong, Leung, Brownridge, Lam, Wong, Lam, Chau, Chan, Cheung, \& Ho, 2008), que filhos de casais violentos tendem a reproduzir essa mesma violência em suas relações, pois aprendem que tal é a forma apropriada de resolverem seus conflitos. A constatação mencionada pode ser feita principalmente em um dos filhos adolescente das entrevistadas, que agredia tanto a mãe quanto a irmã, assim como os colegas do colégio e os vizinhos. A violência, portanto, não se restringiu a ser exercida dentro de casa, mas alcançou a rede social ampliada.

\section{Padrão relacional das famílias de origem materna}

Sob o ponto de vista das participantes acerca da violência perpetrada em suas famílias 
de origem, um dos aspectos emergentes dos dados coletados foi o uso da violência física pelos tios das entrevistadas em suas respectivas esposas, o que caracteriza uma relação abusiva e violenta. Por sua vez, constatou-se a reação dessas esposas às agressões dirigidas a elas, também através do uso da violência física contra os maridos/ companheiros.

O mesmo padrão de relação abusivo e violento foi estabelecido entre o avô materno e a avó materna de uma das entrevistadas, conforme depoimento a seguir:

(...) O vô era muito estúpido (...) Uma vez ele chegou a bater na vó, porque a mãe conta que a irmã dela jogou pedra pra pegar na minha mãe, pegou na cristaleira que o vô tinha comprado. Aí a vó 'cacetou' a mãe, que achou que a culpa era da mãe que provocou a outra. (...) Deu uma surra na mãe, aí diz que o vô deu uma surra nela (avó) porque ela bateu na mãe, entende? (Jasmim)

A partir desse relato, é igualmente possível identificar que a relação de violência estabelecida entre os avós também foi exercida contra a mãe da entrevistada. Além disso, essa mesma participante afirmou que apanhava feito o cão da mãe.

Outro elemento que se destaca da entrevista prestada pela participante em questão é que ela disse desejar não ver repetir a violência física que havia sofrido nos próprios filhos. Apesar disso, admitiu ter agredido fisicamente o filho e ainda deu razões para continuar batendo nele ("tem horas que tu tem que dar umas palmadas"), além de ter dito ser ela quem mais agredia os filhos em casa, e não seu companheiro.

Portanto, é possível verificar que o uso da violência física na família dessa entrevistada ocorreu através de quatro gerações: o avô, que batia na avó, que, por sua vez, batia na mãe; a mãe, que batia nela, e ela, que bate nos filhos. Assim, fica constatado o fato de a violência ocorrer nas diferentes gerações como ato agressivo para lidar com os conflitos familiares, podendo-se compreendê-la como uma herança transmitida de uma geração a outra, caracterizando, com isso, a sua transgeracionalidade, conforme já apontado por estudos realizados por Cecconello et al.(2003), Ferrari e Vecina (2002) e Narvaz e Koller (2006).

\section{Padrão relacional das famílias de origem paterna}

Com respeito às famílias de origem paterna, as relações de maior violência e abuso foram as estabelecidas pelo próprio pai contra a mãe ou madrasta das entrevistadas, que exerciam agressões verbais e físicas contra elas, conforme destacam os relatos a seguir: "A minha mãe, ela apanhou muitos anos do meu pai. (...) Dentro de um quarto, ele agredia muito ela, batia muito nela". (Margarida). "O meu pai e a minha mãe tinham muito disso (agressão). (...) Eu me metia no meio quando era pequena. (...) Via, eu roía as unha, eu não ia no colégio". (Magnólia)

Alguns aspectos que se evidenciam nesses depoimentos são aqueles que possuem semelhanças com a própria história conjugal das entrevistadas. Um desses aspectos diz respeito ao fato de ser comum o pai agredir fisica e verbalmente a mãe dessas participantes, mas nenhuma delas relatou a situação de a mãe ter procurado a polícia ou qualquer outro meio legal para resolver tal problema. A única alternativa legal citada para acabar com as agressões padecidas foi se valerem da separação judicial do marido, mas depois de suportarem por anos a violência provocada por ele. Outra semelhança verificada se deu com relação ao modo apresentado para aguentarem as agressões perpetradas pelos maridos/ companheiros, ou seja, algumas mulheres reagiram à violência da qual eram vítimas igualmente através do uso da agressão física. 
Outro ponto de conexão entre a história conjugal dos pais das entrevistadas com a história conjugal destas foi que algumas delas admitiram terem visto certas agressões perpetradas pelo pai contra a mãe, e que sofriam com isso. Como visto, uma das participantes confessou que "roía as unhas" e que "não ia ao colégio" ao ver os pais se agredindo, o que pode ser equiparado ao que também aconteceu com os filhos dessas mulheres, que sofreram repercussões emocionais e comportamentais em função das agressões verbais e/ou físicas desferidas pelo pai/padrasto.

Pode-se dizer, assim, que houve um padrão de relacionamento familiar de violência que afetou as participantes, e que, em consequência, ressoou no desenvolvimento dos próprios filhos, conforme apontado anteriormente. Compreendeu-se que a violência física era utilizada como uma forma de resolver conflitos, especialmente entre o casal, e que cabia às mulheres tolerarem as agressões sofridas ou, em alguns casos, revidá-las.

Contudo, o pai não batia apenas na mãe das entrevistadas. Em pelo menos um caso, ele igualmente exerceu violência física nos próprios filhos. Sendo assim, a agressão perpetrada pelo pai também atingiu os irmãos e as irmãs de uma das participantes e influenciou no modo como estes estabeleceram relação com as respectivas esposas e maridos, assim como com os filhos, já que foi elevado o número de irmãos e irmãs dessa entrevistada que se relacionavam através da violência com o cônjuge e com os seus descendentes.

Nesse caso, o que se destacou dos dados analisados foi o fato de o irmão, na maior parte das vezes, ter sido o agente da agressão, e de a irmã ter sido a pessoa agredida, mantendo-se, com isso, o padrão familiar de o homem agredir a mulher dentro da relação conjugal. Entretanto, também houve alguns depoimentos de situações em que a mulher agredia fisicamente o homem, ou como resposta a uma agressão dirigida a ela pelo marido/companheiro, ou como principal agente da violência perpetrada. Além disso, os irmãos e as irmãs das participantes buscaram resolver as diferenças com os cônjuges igualmente através da separação judicial. Em somente um caso foi relatada a procura pela polícia como forma de resolver o conflito estabelecido entre o casal.

Através das entrevistas realizadas, também se pôde observar o padrão relacional das famílias de origem dos maridos/companheiros das participantes. O retrato apresentado não foi muito diferente do visto com as famílias de origem materna e paterna das entrevistadas, ou seja, o pai geralmente batia na mãe, e os irmãos agrediam as esposas.

Outra analogia verificada na família de origem dos agressores com a família de origem das entrevistadas foi o fato de algumas mulheres revidarem as agressões sofridas dos maridos/ companheiros, sendo que não houve o relato de, nessas situações, ter sido solicitada ajuda policial para intervir no problema, mas de procurar resolver seus atritos através da separação judicial.

Pode-se constatar, ainda, que a transgeracionalidade da violência acontece da mesma forma nas famílias de origem dos maridos/ companheiros das participantes, já que as agressões ocorriam do pai contra a mãe e do pai contra os próprios filhos; estes, por sua vez, tornaram-se agressores das esposas/ companheiras (as entrevistadas) e também dos descendentes. Sendo assim, a partir do conjunto desses dados, é possível confirmar o que estudos da área (Ministério da Saúde, 2002; Narvaz \& Koller, 2006; Silva et al., 2007) apontam: uma história familiar em que a violência é frequentemente exercida entre seus integrantes propicia a repetição do 
modelo em seus próprios relacionamentos afetivos nas gerações seguintes.

\section{Considerações finais}

Entende-se que os dados deste estudo precisam ser contextualizados e compreendidos no universo da pesquisa qualitativa. Desse modo, a representatividade desta pesquisa está no conjunto de significados das narrativas obtidas de um grupo de mulheres que se dispuseram a participar do estudo, cabendo o destaque especial de que o acesso a essas participantes foi permeado de dificuldades, devido, eminentemente, à temática abordada, em que o silêncio e o sentimento de vergonha de expor suas vidas marcadas pela violência são aspectos relevantes.

Concomitantemente, deve-se ter em conta que o estudo tratou de mulheres que cresceram e vivem em um contexto sociocultural de uma região do sul do Brasil, com valores decorrentes do processo histórico/social das diferentes culturas que para ali convergem. Portanto, a configuração assumida pelos elementos de análise levantados a partir das narrativas deve ser considerada dentro de referido contexto. Isso implica dizer que os contextos socioculturais engendram expressões específicas da violência contra a mulher, assim como modos específicos de reação frente a esse agravo.

Apesar das peculiaridades desta pesquisa, considera-se que os dados levantados podem ser somados ao campo do conhecimento existente, para evidenciar indicadores de violência contra a mulher muitas vezes subjugada a preconceitos e, principalmente, ao desconhecimento e à falta de preparo profissional para melhor enfrentar e/ou lidar com diferentes facetas ou formas da violência contra a mulher.
Levando-se em conta que os principais agressores foram os homens, e as vítimas de violência, na maioria, as mulheres, e que estas toleraram por um longo período as agressões a elas dirigidas, reforçam-se, com isso, as relações de gênero como um ponto fundamental a ser levado em consideração no momento de pensar e implementar ações acerca das políticas destinadas a proteger a população feminina.

A identificação da transgeracionalidade da violência e de como a agressão contra a mulher dentro do grupo familiar pode afetar seus integrantes chama a atenção igualmente para a necessidade de se analisar o impacto que a violência pode gerar nas pessoas próximas à mulher que padece de agressões, tanto no momento da realização de novas pesquisas sobre o tema, quanto nas situações de intervenção no referido agravo.

Além disso, seria relevante aprofundar cada vez mais o estudo sobre os elementos que levam certas mulheres a se submeterem a uma relação conjugal e/ou familiar violenta e os que levam alguns homens a tentarem resolver seus conflitos por meio da agressão, assim como pesquisar o papel das redes de suporte social quanto à sua efetividade junto a mulheres em situação de violência e as formas possíveis de interrupção da transgeracionalidade desta última, para aumentar o conhecimento sobre o tema e para possibilidades de transformação desse fenômeno. 


\section{Ana Cláudia Wendt dos Santos}

Psicóloga e mestre em Psicologia pela Universidade Federal de Santa Catarina, Santa Catarina - SC - Brasil. E-mail: aclws@ig.com.br

\section{Carmen Leontina Ojeda Ocampo Moré}

Doutora e professora adjunta IV da Universidade Federal de Santa Catarina, Santa Catarina - SC - Brasil. E-mail: carmenloom@gmail.com

\section{Endereço para envio de correspondência:}

Rua José Batista Rosa, 432, Trindade. Florianópolis - Santa Catarina - Brasil. CEP 88.036-150

Recebido 29/6/2009, 1a Reformulação 11/1/2011, Aprovado 31/3/2011.

\section{Referências}

Alberdi, I. (2005). Cómo reconocer y cómo erradicar la violencia contra las mujeres. In Programa de Prevención de la obra social "la Caixa". Violencia: tolerancia cero (pp. 9-87). Barcelona: Fundación "la Caixa".

Aldrighi, T. (2006). Família e violência. In C. M. O. Cerveny (Org.), Família e (pp. 197-220). São Paulo: Casa do Psicólogo.

Asen, K. E., \& Tomson, Peter (1997). La familia dentro de nosotros. Genogramas. In K. E. Asen, \& M. Tomson, Intervención familiar: Guía práctica para los profesionales de la salud (pp. 39-51). Barcelona, Buenos Aires, México: Paidós.

Azevedo, M. A. (1985). Mulheres espancadas - a violência denunciada. São Paulo: Cortez.

Bedone, A. J. \& Faúndes, A. (2007, fevereiro). Atendimento integral às mulheres vítimas de violência sexual: Centro de Assistência Integral à Saúde da Mulher, Universidade Estadual de Campinas. Cadernos de Saúde Pública, 23(2), 465-469. Recuperado em 28 julho 2007, de http://www. scielo.br/scielo/

Biasoli-Alves, Z., M. M. (1998). A pesquisa em psicologia análise de método e estratégias na construção de um conhecimento que se pretende científico. In G. Romanelli, \& Z. M. M., Biasoli-Alves (Orgs.), Diálogos metodológicos sobre prática de pesquisa (pp. 135-157). Ribeirão Preto: Legis Summa.

Cantera, L. M. (2007). Casais e violência: um enfoque além do gênero. Porto Alegre: Dom Quixote.

Carneiro, A., \& Oliveira, S. (2008, outubro). Violência intrafamiliar baseada em gênero com implicação de risco de vida: mulheres abrigadas na Casa Abrigo Maria Haydeé/Rio Mulher/ Rio de Janeiro. In XVI Encontro Nacional de Estudos Populacionais, ABEP. Caxambú, MG.

Carter, B., \& McGoldrick, M. (1995). A mudança no ciclo de vida familiar - uma estrutura para a terapia familiar (2a ed., pp. 7-29). Porto Alegre: Artmed.

Cecconelo, A. M., De Antoni, C., \& Koller, S. H. (2003). Práticas educativas, estilos parentais e abuso físico no contexto familiar. Psicologia em Estudo, 8(Esp.), 45-54.

Ferrari, D. C. A. \& Vecina, T. C. C. (2002). O fim do silêncio na violência familiar - teoria e prática. São Paulo: Ágora.

Fuster, E. G. (2002). Las victimas invisibles de la violencia familiar: Extraño iceberg de la violencia doméstica. Barcelona: Paidós Ibérica.

Marcos, L. R. (2005). Semillas y antídoto de la violencia en la intimidad. In Programa de Prevención de la Obra Social "la Caixa". Violencia: tolerancia cero (pp. 89-128). Barcelona: Fundación "la Caixa".

Ministério da Saúde. (2002). Violência intrafamiliar - orientações para a prática em serviço. Cadernos de Atenção Básica, n. 8, (Série A - Normas e Manuais Técnicos, n. 131). Brasília, DF.
Monteiro, C. F. De, \& Souza, I. E. de O. (2007, jan./mar). Vivência da violência conjugal: fatos do cotidiano. Texto Contexto Enfermagem, 16(1), 26-31. Recuperado em 22 março 2008, de http://www.scielo.br/scielo/

Moré, C. L. O. O. (2000). Atendendo a demanda: proposta de um modelo de sistematização de intervenção psicológica junto a postos de saúde comunitários. Tese de doutorado, Pontifícia Universidade Católica de São Paulo, São Paulo.

Muhr, T. (2004). ATLAS/ti the knowledge workbench. V 5.0 Quick tour for beginners. Berlin: Scientific Software Development.

Narvaz, M. G., \& Koller, S. H. (2006). A concepção de família de uma mulher-mãe de vítimas de incesto. Psicologia: Reflexão e Crítica, 19(3), 395-406.

Santos, C. M., \& Izumino, W. P. (2005). Violência contra as mulheres e violência de gênero: notas sobre estudos feministas no Brasil. E.I.A.L. Estudios Interdisciplinarios de América Latina y EI Caribe, 16(1). Recuperado em 09 novembro 2008, de http:// www.nevusp.org/downloads/down083.pdf

Scaranto, C. A. A., Biazevic, M. G. H., \& Michel-Crosato, E. (2007). Percepção dos agentes comunitários de saúde sobre a violência doméstica contra a mulher. Psicologia: Ciência e Profissão, 27(4), 694-705.

Silva, L. L. da, Coelho, E. B. S., \& Caponi, S. N. C. de (2007, jan./ abr.). Violência silenciosa: violência psicológica como condição da violência física doméstica. Interface - Comunicação, Saúde, Educação, 11(21), 93-103.

Sluzki, C. E. (1997). A rede social na prática sistêmica. (C. Berliner, Trad.). São Paulo: Casa do Psicólogo.

Souza, C. de M., \& Adesse, L. (2005). Violência sexual no Brasil: perspectivas e desafios. Rio de Janeiro: Ipas Brasil.

Strauss, A. L., \& Corbin, J. (1990, mar.). Grounded theory research: Procedures, canons and evaluative criteria. Qualitative Sociology, 13(1), 3-21

Tiwari, A., Chan, K. L., Fong, D., Leung, W. C., Brownridge, D. A. Lam, H., Wong, B., Lam, C. M., Chau, F., Chan, A., Cheung, K. B., \& Ho, P. C. (2008). The impact of psychological abuse by an intimate partner on the mental health of pregnant women. BJOG International Journal of Obstetrics and Gynaecology, 115, 377-384. Recuperado em 20 abril 2008, de http://www. blackwell-synergy.com

Villela, W. V., \& Lago, T. (fev. de 2007). Conquistas e desafios no atendimento das mulheres que sofreram violência sexual. Cadernos de Saúde Pública, 23(2), 471-475. 